\title{
Urbanization and Economic Growth in China-An Empirical Research Based on VAR Model
}

\author{
Li Yang $\mathrm{Zi}^{1}$ \\ ${ }^{1}$ Department of Urban Planning, Tsinghua University, Beijing, China \\ Correspondence: Li Yang Zi, Department of Urban Planning, Tsinghua University, Beijing, China. E-mail: \\ liyangzi@mail.tsinghua.edu.cn
}

Received: January 17, 2017

Accepted: February 10, 2017

Online Published: February 20, 2017

doi:10.5539/ijef.v9n3p210

URL: https://doi.org/10.5539/ijef.v9n3p210

\begin{abstract}
This paper takes the relation between urbanization and economic growth in China as the object of study. By using the time series data ranging from 1982 to 2014 and building VAR model, it analyzes, respectively, the dynamic relations between economic growth and the urbanization rate of resident population, the urbanization rate of land and the quality of urbanization. The paper comes up with the following conclusions: there exists a unidirectional causality between resident population urbanization and China's economic growth, the former promoting the long-term growth of the latter; unidirectional causality also exists between land urbanization rate and China's economic growth. However, different from resident population urbanization rate, it is the economic growth of China that promotes the increase of land urbanization rate and the increase of land urbanization rate cannot promote China's economic growth; the relation between the quality of urbanization and China's economic growth is a two-way causality. The improvement of urbanization quality has a cumulative positive effect on the economic growth of China, while economic growth has a negative effect on the improvement of urbanization quality in the short term and positive effect on economic growth in the long term.
\end{abstract}

Keywords: resident population urbanization, household registered population urbanization, land urbanization, quality of urbanization, economic growth

\section{Introduction}

Urbanization is one of the themes of the economic and social development in China and in the world. According to the forecast of UNFPA, by $2050,75 \%$ of the world's population will be living in the urban area. From the perspective of social development process in China, the more than three decades since the reform and opening-up have witnessed a roaring development of urbanization. By the end of 2015, the urbanization rate of China had reached $56.1 \%$, with the resident population in cities and towns arriving at 770 million. On the one hand, urbanization makes industries and population gather towards cities and generates scale effect, which has positive effects on economic growth; on the other hand, rapid urbanization also brings problems such as environmental pollution, overcrowding, etc., which has negative effects on economic growth. Therefore the in-depth study of the relation between urbanization and economic growth has great practical significance for increasing the promotion of urbanization to economic growth and realizing the harmonious development of the two. This paper takes China as an example to analyze the relation between urbanization and economic growth, provides answer to the question whether urbanization promotes economic growth or the other way round and the size of its effect, and puts forward police suggestions on how China should promote urbanization in the future.

\section{Related Literatures}

The relation between urbanization and economic growth has always been a focus of domestic and foreign scholars' researches. As early as 1956, Lampard studied the relation between urbanization and economic growth in the U.S. and concluded that economic growth promotes urbanization in the U.S. Bertinelli et al. (2008) thought that there exists a critical value in the role of urbanization in economic growth; urbanization can have effect on economic growth only when urbanization has developed to a certain degree. By empirical test, Bloom et al. (2008) concluded that there is no remarkable evidence showing urbanization will have effect on economic growth; the policy trying to influence economic growth by raising or reducing urbanization rate might be useless. In China, different scholars have adopted different data and methods to conduct in-depth studies of the relation 
between urbanization and economic growth. Lin et al. (2013) analyzed the relation between urbanization and economic growth in China by using the data from 1978 to 2008 and ordinary least squares. Their opinion is that there are no obvious characteristics of urbanization as the direct power source of China's economic growth and urbanization is more a result of economic development. Deng et al. (2015) analyzed the relation between urbanization and economic growth from the perspective of urbanization's influence on China's economic growth pattern. Urbanization rate was taken as explanatory variable and total factor productivity as explained variable to build the model. The conclusion is that the urbanization in China is relatively extensive and hinders the transformation of economic growth pattern. Zhu et al. (2011) built econometric model by using provincial panel data from 2000 to 2009 and pointed out that there exists a long-term stable equilibrium relation between China's urbanization process and economic development level. Each one percentage point in the increase of urbanization rate of our country can sustain $7.1 \%$ of economic growth. Wang et al. (2013) divided urbanization rate into population urbanization and land urbanization and analyzed urbanization's influence on economic growth by using provincial panel data from 1996 to 2011. The conclusion is that population urbanization has an obvious lifting effect on China's economic growth and the effect of land urbanization on economic growth is not obvious. Jiang et al. (2014) selected the time series data of urbanization rate and per capita GDP from 1978 to 2012 to build model and concluded that a positive correlation exists between China's urbanization and economic growth. Some scholars also introduced other variables when analyzing the relation between urbanization and economic growth. For example, Guo et al. (2015) analyzed the relation between family planning policy, urbanization and economic growth. The conclusion is that due to urbanization process, family planning rates in urban and rural areas have different long-term influence on population and economic growth; the increase in urbanization rate will offset the influence of increase in urban fertility rate, after improving the urban family planning fertility rate.

In summary, the existing researches on the relation between urbanization and economic growth have two outstanding features. Firstly, the research conclusions are not consistent. Some scholars think urbanization plays a facilitating role in economic growth, while some think urbanization is not the source and power of economic growth but rather the result of it. Secondly, most researches adopt single index method, measuring the urbanization level of a country or region by the proportion of urban population of a country or region in the total population and ignoring the triple attributes of urbanization in China, i.e. urbanization in China includes the urbanization of resident population, household registered population and land. The urbanization of resident population is the urbanization in common sense, representing the increase of total urban population. The urbanization of household registered population is related with the special household registration system in China. Household registration is closely related with social welfare. Only population with city household registration can enjoy the related welfare in terms of pension, housing, children's education, etc. Therefore in China, the urbanization of household registered population can better reflect the quality of urbanization. Land urbanization refers to the enlargement of urban space. In our opinion, the different conclusions of existing researches are exactly the result of incomplete analysis of the triple attributes of urbanization in China. So, the innovation of the study in this paper is that urbanization was divided into three behaviors: resident population urbanization, household registered population urbanization and land urbanization. The role of urbanization in economic growth was comprehensively analyzed, reflecting not only the role of increase of urban resident population, but also the role of increase of household registered population, i.e. urbanization quality and explaining the influence of urban space enlargement at the same time.

\section{The Status Quo of Urbanization in China}

Rapid urbanization is the deepest change of China's economy and society in the past more than three decades. Urbanization process has changed the patterns of population and economy in China, making China transform from agricultural society to urban society and from a primarily agricultural country to a country primarily based on industry and services, and exerting profound influence on economic growth. By the end of 2014, the urbanization rate of resident population in China was 54.77\%, an increase of 1.6 times comparing with $21.2 \%$ in 1982; the land urbanization rate was $27.04 \%$, an increase of 10.5 times comparing with $2.34 \%$ in 1982 ; the urbanization rate of household registered population was $36.33 \%$, an increase of 1.1 times comparing with $17.6 \%$ in 1982. Apart from rapid increase, the urbanization in our country also has two characteristics: one is that the speed of population urbanization is lower than the speed of land urbanization; the other is that the urbanization rate of household registered population is lower than the urbanization rate of resident population.

The urbanization speed of population is slower than that of the land. In 2014, the urbanization rate of population in China had a growth of $1.94 \%$ on year-on-year basis, and the urbanization rate of land had a growth of $4.01 \%$ on year-on-year basis. In terms of year-on-year growth rate, the urbanization rate of population is slower than that of the land by 2.07 percentage points. To show this feature of urbanization in China in a more visualized way, 
we demonstrated the data from 1982 to 2014 of the year-on-year growth rate regarding urbanization rate of population and of land in a figure. Taking the year-on-year growth rate of land urbanization rate as the vertical axis and the year-on-year growth rate of population urbanization rate as the horizontal axis, the value of the data point is represented by the ratio of the year-on-year growth rate of population urbanization rate to the year-on-year growth rate of land urbanization rate. A larger data point represents a larger ratio. Then we drew the equation $\mathrm{Y}=\mathrm{X}$ oblique line. When data points fall exactly on this oblique line, it means the year-on-year growth rate of population urbanization rate equals to that of land urbanization rate; when data points fall in the region above this oblique line, it means the year-on-year growth rate of population urbanization rate is lower than that of land urbanization rate; when data points fall in the region under this oblique line, it means the year-on-year growth rate of population urbanization rate is higher than that of land urbanization rate. As is shown in Fig. 1, except 4 data points, all the other data points fall in the region above $\mathrm{Y}=\mathrm{X}$, indicating the imbalance between population urbanization rate and land urbanization rate in China.

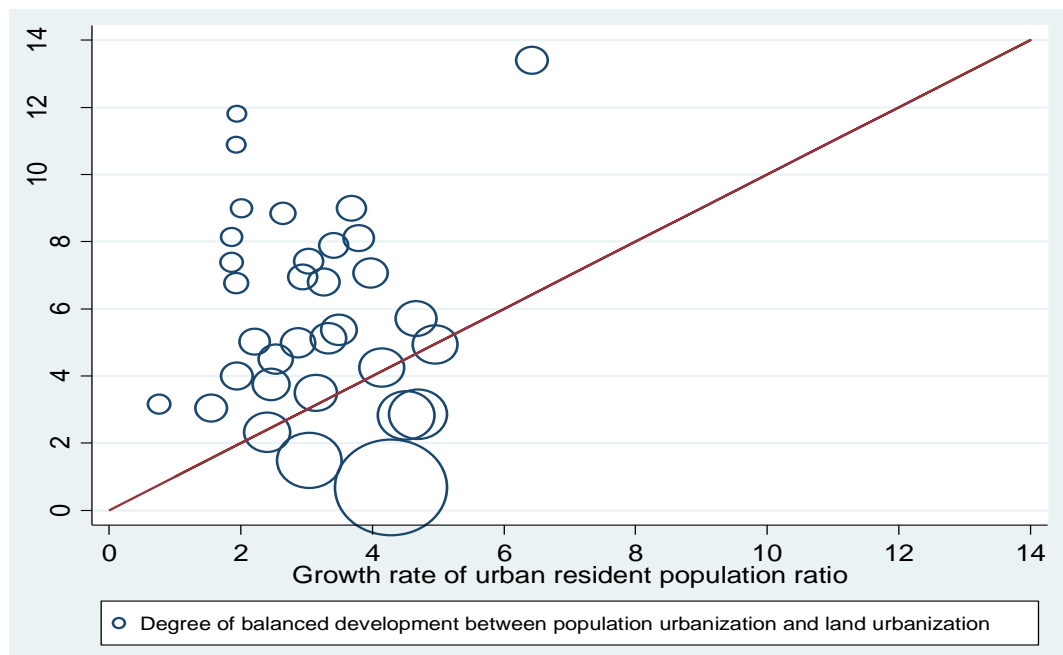

Figure 1. Imbalance between population urbanization rate and land urbanization rate in China

Note. Comparison of the Growth Rate of Resident Population Urbanization Rate with Land Urbanization Rate in China.

The urbanization rate of household registered population is lower than that of the resident population. In 2014, the urbanization rate of household registered population was $36.63 \%$, and the urbanization rate of resident population was $54.77 \%$. The urbanization rate of household registered population is lower than that of the resident population by 18.14 percentage points. Similarly, to show this feature of urbanization in China in a more visualized way, we demonstrated the data from 1982 to 2014 of the urbanization rate of household registered population and of resident population in a figure. Taking the urbanization rate of household registered population as the vertical axis and the urbanization rate of resident population as the horizontal axis, the value of the data point is represented by the ratio of household registered population urbanization rate to resident population urbanization rate. A larger data point represents a larger ratio. Usually, the ratio of household registered population urbanization rate to resident population urbanization rate is also used to measure the quality of urbanization. The higher the ratio, the higher the urbanization quality, and the lower ratio means lower urbanization quality. Meanwhile, we drew the equation $\mathrm{Y}=\mathrm{X}$ oblique line. When data points fall exactly on this oblique line, it means the year-on-year growth rate of household registered population urbanization rate equals to that of resident population urbanization rate; when data points fall in the region above this oblique line, it means the year-on-year growth rate of household registered population urbanization rate is higher than that of resident population urbanization rate; when data points fall in the region under this oblique line, it means the year-on-year growth rate of household registered population urbanization rate is lower than that of resident population urbanization rate. As is shown in Fig. 2, all the data points fall in the region under $Y=X$, indicating the current situation of low quality urbanization in China. 


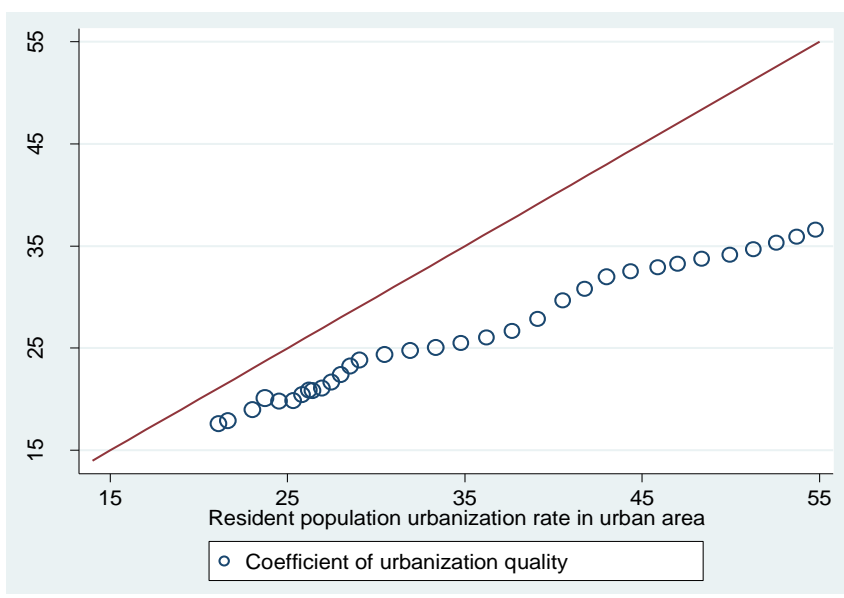

Figure 2. Quality of urbanization in China

Note. Comparison of Resident Population Urbanization Rate with Household Registered Population Urbanization Rate in China.

\section{Empirical Test}

Based on research of the relation between urbanization and economic growth in China, this paper selected the growth rate of land urbanization rate (GRU) as the index representing the speed of land urbanization in China; the growth rate of resident population urbanization rate (GRP) as the index representing the urbanization rate of population in China; the ratio of household registered population urbanization rate to resident population urbanization rate (Quality) to represent the urbanization quality in China. The closer to 1 the ratio of household registered population urbanization rate to resident population urbanization rate, the higher the quality of urbanization. When the ratio is below 1 , the smaller the value is, the lower the quality of urbanization will be. Meanwhile, the moving average of per capita GDP which moves forwards to the following five years (AGRGDP) was selected to represent China's economic growth. The reason for this selection is to avoid reverse causality.

Table 1. Descriptive statistics of variables

\begin{tabular}{clccccc}
\hline Variable & \multicolumn{1}{c}{ Description } & Unit & Mean & Std. Dev. & Min & Max \\
\hline AGRGDP & Growth rate of per capita GDP & $\%$ & 9.05 & 1.50 & 6.32 & 11.16 \\
GRU & Growth rate of land urbanization rate & $\%$ & 5.97 & 2.97 & 0.68 & 13.40 \\
GRP & Growth rate of resident population urbanization rate & $\%$ & 3.08 & 1.20 & 0.76 & 6.43 \\
Quality & Quality of urbanization & $\%$ & 75.65 & 5.43 & 66.87 & 84.77 \\
\hline
\end{tabular}

Note. In the following text, all the $* * *$ represents $1 \%$ significance level; ** represents $5 \%$ significance level; *represents $10 \%$ significance level.

The data time-span covers 1982 to 2014, which are time series data of 33 years in total. All the data were obtained from China Statistical Yearbook 1983-2015. The descriptive statistics of the variables are shown in Table 1. The average AGRGDP is $9.05 \%$, representing the high-speed economic growth in the past three decades in China; the average growth rate of land urbanization rate and resident population urbanization rate are $5.97 \%$ and $3.08 \%$ respectively, representing that land urbanization rate is of higher speed than resident population urbanization rate; the average of Quality is $75.65 \%$, which is below 1 and indicates that the urbanization quality in our country is not satisfactory and in urgent need of further improvement.

Table 2. Unit root test of the variables

\begin{tabular}{ccccc}
\hline \multirow{2}{*}{ Variable } & DF-GLS tau & $1 \%$ & $5 \%$ & $10 \%$ \\
& Test Statistic & Critical Value & Critical Value & Critical Value \\
\hline AGRGDP & $-4.407 * * *$ & -3.77 & -3.457 & -3.092 \\
GRU & $-3.169 * *$ & -3.77 & -2.967 & -2.632 \\
GRP & $-2.93 * *$ & -3.77 & -2.82 & -2.453 \\
Quality & $-3.346^{* *}$ & -3.77 & -3.197 & -2.864 \\
\hline
\end{tabular}


For the analysis of time series data, the unit root test needs to be conducted in the first place to make a judgment of the stationarity of the data. When all of the time series data are stationary sequences, the analysis method of vector autoregression model (VAR model) can be adopted; when the time series data are not stationary but integrated of the same order, the analysis method of vector error correction model (VECM model) can be adopted. By the mutual reflection of ADF test and DF-GLS test, as is shown in Table 2, AGRGDP, GRU, GRP and Quality all reject null hypothesis of the existence of unit root at 5\% significance level. Therefore they are all stationary time series, i.e. I(0). As a result, this paper adopted VAR model to analyze the relation between urbanization and economic growth in China. VAR model is a non-structural dynamic analysis method for dealing with the analysis and forecasting of multiple relevant time series economic indicators.

Firstly, after the decision to use VAR model, the order of VAR model is estimated based on information criterion, and the concrete form of VAR model is thereby decided. According to AIC, HQIC, SIC, etc. information criterion minimization, we chose VAR model with lag order 2, as is shown in Equation 1.

$$
\left(\begin{array}{c}
\text { AGRGDP }_{\mathrm{t}} \\
\mathrm{GRU}_{\mathrm{t}} \\
\mathrm{GRP}_{\mathrm{t}} \\
\text { Quality }_{\mathrm{t}}
\end{array}\right)=\Phi_{0}+\Phi_{1}\left(\begin{array}{c}
\text { AGRGDP }_{\mathrm{t}-1} \\
\mathrm{GRU}_{\mathrm{t}-1} \\
\mathrm{GRP}_{\mathrm{t}-1} \\
\text { Quality }_{\mathrm{t}-1}
\end{array}\right)+\Phi_{2}\left(\begin{array}{c}
\mathrm{AGRGDP}_{\mathrm{t}-2} \\
\mathrm{GRU}_{\mathrm{t}-2} \\
\mathrm{GRP}_{\mathrm{t}-2} \\
\text { Quality }_{\mathrm{t}-2}
\end{array}\right)+\left(\begin{array}{c}
\mathrm{e}_{1 \mathrm{t}} \\
\mathrm{e}_{2 \mathrm{t}} \\
\mathrm{e}_{3 \mathrm{t}} \\
\mathrm{e}_{4 \mathrm{t}}
\end{array}\right)
$$

Secondly, estimate VAR model and conduct test, particularly the stability test of VAR system. As is shown in Fig. 3 , all the eigenvalues are within the unit root, so the VAR system is stable.

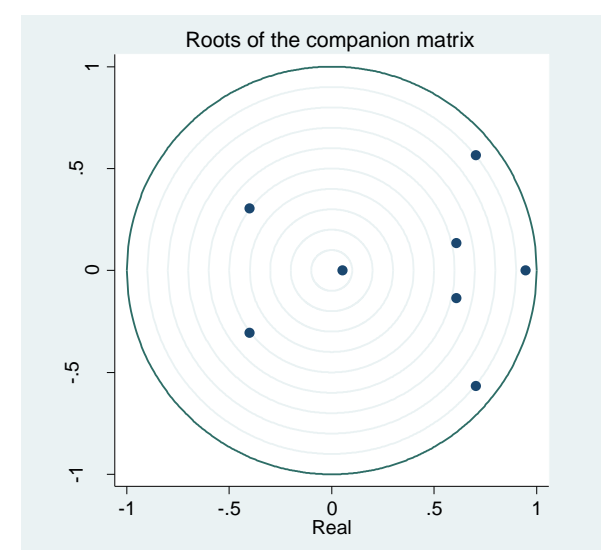

Figure 3. Roots of the companion matrix

Thirdly, investigate the Granger Causality among the variables. As in Table 3, the null hypothesis is rejected at 5\% significance level, i.e. the growth rate of resident population urbanization rate and the quality of urbanization are not the reason of the changes in the growth rate or per capita GDP, but it cannot be rejected that the growth rate of land urbanization is not the reason of the changes in the growth rate of per capita GDP. Meanwhile, at 5\% significance level, it is rejected that the growth rate of per capita GDP is not the reason of the changes in the growth rate of land urbanization and the quality of urbanization, but it cannot be rejected that the growth rate of per capita GDP is not the reason of the changes in the growth rate of resident population urbanization rate. In other words, there exists a unidirectional causality between land urbanization and economic growth in China. It is the urbanization of resident population that promotes the economic growth and not the other way round; there exists a two-way causality between the quality of urbanization and economic growth with reciprocal causation and mutual promotion.

Table 3. The Granger causality wald tests results

\begin{tabular}{ccccc}
\hline Equation & Excluded & Chi2 & DF & \multicolumn{1}{c}{ Prob >Chi2 } \\
\hline AGRGDP & GRU & 4.5789 & 2 & 0.101 \\
AGRGDP & GRP & 16.186 & 2 & $0.000^{* * *}$ \\
AGRGDP & Quality & 13.857 & 2 & $0.001^{* * *}$ \\
GRU & AGRGDP & 7.9068 & 2 & $0.019^{* *}$ \\
GRP & AGRGDP & 1.9168 & 2 & 0.383 \\
Quality & AGRGDP & 16.684 & 2 & $0.000^{* * *}$ \\
\hline
\end{tabular}


Finally, by building impulse response functions, we analyzed the mutual relations in detail between several pairs of variables which have causal relations, and obtained the dynamic trajectory and the graph of impulse response functions of the relation between urbanization and economic growth in China. In the graph of impulse response functions, horizontal axis represents the number of lag stages of the shock effect; vertical axis represents the responses from variables; full line represents impulse response functions; dotted line represents plus-minus two times standard deviation of the departure.

As is shown in Fig. 4, when exerting one standard deviation shock to the growth rate of resident population urbanization rate in the current stage, the growth rate of per capita GDP declines in the first 4 stages and starts to grow stably after the 5th stage. It indicates that certain shock of resident population urbanization rate will bring homodromous shock to the growth of per capita GDP, i.e. the increase of resident population urbanization rate will have stable pulling effects on the growth of per capita GDP after 5 years.

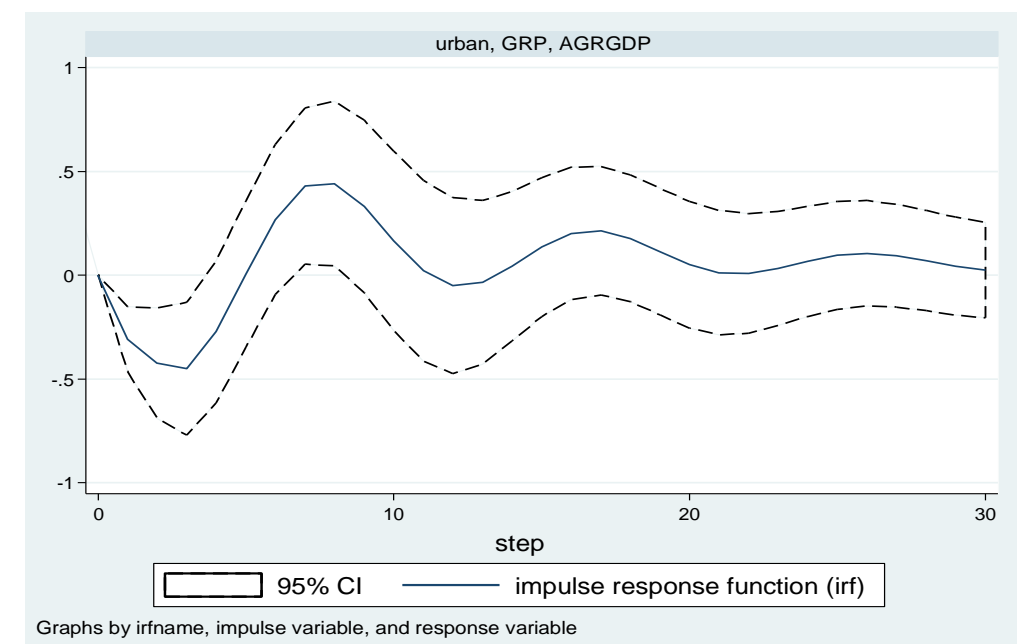

Figure 4. The graph of impulse response function of AGRGDP to GRP

As is shown in Fig. 5, when exerting one standard deviation shock to the quality of urbanization in the current stage, the growth rate of per capita GDP declines in the first 5 stages and starts to grow after the 6th stage. It indicates that certain shock of the quality of urbanization will bring homodromous shock to the growth of per capita GDP, i.e. the improvement of urbanization quality will have stable pulling effects on the growth of per capita GDP after 6 years.

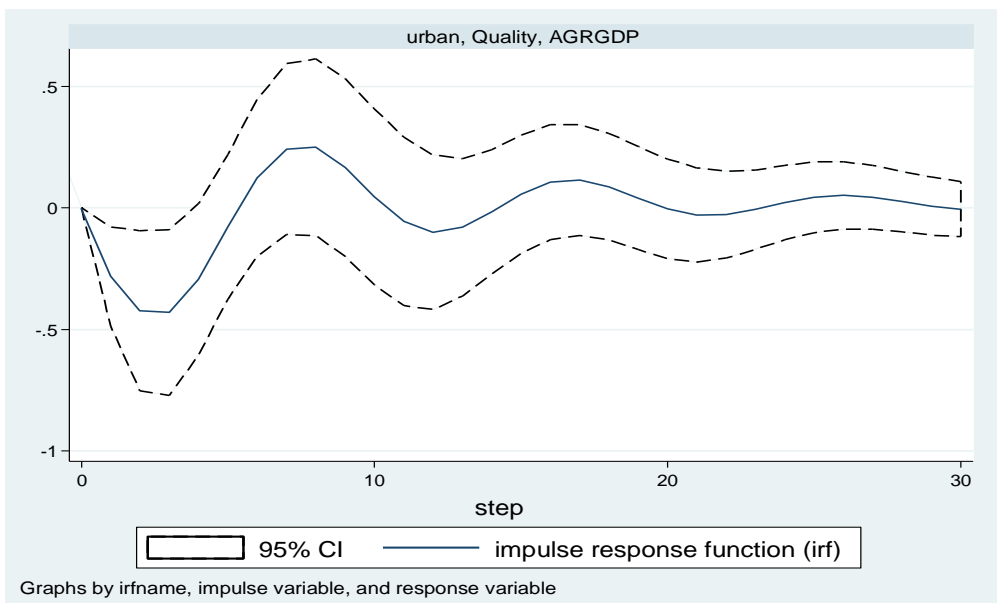

Figure 5. The graph of impulse response function of AGRGDP to quality

As is shown in Fig. 6, when exerting one standard deviation shock to the growth rate of per capita GDP in the current stage, the growth rate of land urbanization rate continues to increase in the first 4 stages and the 
fluctuation approaches zero afterwards. It indicates that certain shock of the growth rate of per capita GDP will bring homodromous shock to the growth rate of land urbanization rate, i.e. the growth of per capita GDP have promoted the speed of land urbanization.

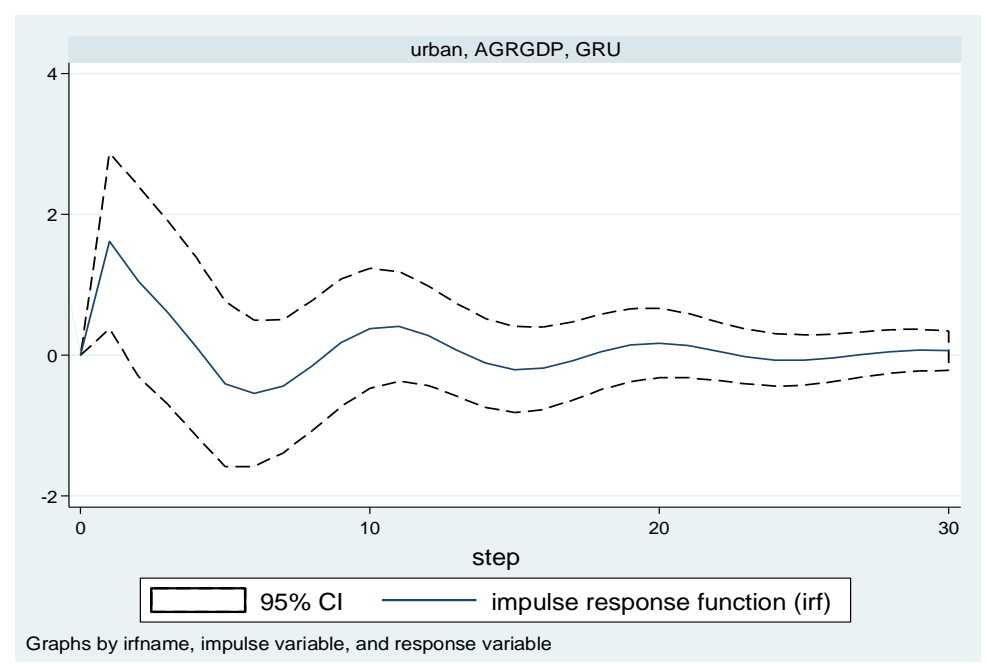

Figure 6. The graph of impulse response function of GRU to AGRGDP

As is shown in Fig. 7, when exerting one standard deviation shock to the growth rate of per capita GDP in the current stage, the quality of urbanization has a positive response and always approaches zero from the positive direction. It indicates that certain shock of the growth rate of per capita GDP will bring homodromous shock to the quality of urbanization, i.e. the growth of per capita GDP have promoted continuous improvement of urbanization quality.

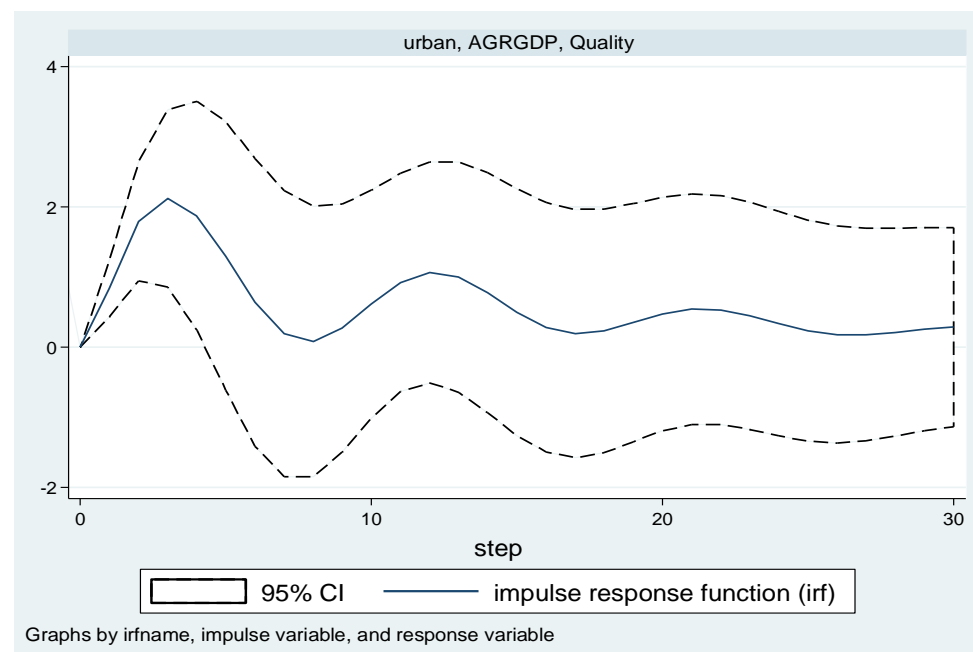

Figure 7. The graph of impulse response function quality to AGRGDP

So far, by empirical test, we have analyzed the relation between urbanization and economic growth in China. Table 4 contains the values by stages and cumulative values of the impulse response functions among variables. From the perspective of cumulative values, it can be seen that population urbanization rate has cumulative positive effect on the growth of per capita GDP. However, the quality of urbanization has cumulative negative effect on the growth of per capita GDP, because the improvement of urbanization quality brings oversize decline in per capita GDP at initial stage. The growth of per capita GDP has cumulative positive effect on land urbanization and the improvement of urbanization quality. 
Table 4. Impulse response values of the relation between urbanization and economic growth

\begin{tabular}{ccccccccc}
\hline & \multicolumn{2}{c}{ GRP to AGRGDP } & \multicolumn{2}{c}{ Quality to AGRGD } & \multicolumn{2}{c}{ AGRGDP to GRU } & \multicolumn{2}{c}{ AGRGDP to Quality } \\
\cline { 2 - 8 } step & Cur & Cum & Cur & Cum & Cur & Cum & Cur & Cum \\
\hline 1 & -0.308 & -0.308 & 1.619 & 1.619 & 0.839 & 0.839 & -0.282 & -0.282 \\
2 & -0.424 & -0.732 & 1.052 & 2.671 & 1.795 & 2.634 & -0.423 & -0.705 \\
3 & -0.451 & -1.183 & 0.607 & 3.279 & 2.123 & 4.758 & -0.430 & -1.135 \\
4 & -0.273 & -1.456 & 0.117 & 3.396 & 1.876 & 6.634 & -0.294 & -1.429 \\
5 & 0.006 & -1.450 & -0.409 & 2.987 & 1.299 & 7.933 & -0.077 & -1.505 \\
6 & 0.268 & -1.182 & -0.543 & 2.444 & 0.638 & 8.571 & 0.124 & -1.381 \\
7 & 0.429 & -0.753 & -0.442 & 2.002 & 0.193 & 8.764 & 0.243 & -1.138 \\
8 & 0.441 & -0.312 & -0.148 & 1.854 & 0.081 & 8.844 & 0.250 & -0.888 \\
9 & 0.331 & 0.019 & 0.175 & 2.029 & 0.270 & 9.114 & 0.167 & -0.722 \\
10 & 0.165 & 0.185 & 0.379 & 2.409 & 0.614 & 9.728 & 0.046 & -0.676 \\
\hline
\end{tabular}

Note. Cur means Current, Cum means Cumulative.

\section{Conclusions}

By empirical test, we can obtain the following conclusions. Firstly, there exists a unidirectional causality between resident population urbanization and China's economic growth, the former promoting the long-term growth of the latter, and not the other way round. In the short term, resident population urbanization rate has a negative effect on economic growth and in the long term, a positive effect. The reason of this conclusion is that the population urbanization requires relevant supporting public investment, such as infrastructure construction, and therefore has negative effect on economic growth in the short term. However, along with the population gathering towards cities, population transfer from primary industry to tertiary industry. It makes the positive factors promoting economic growth be reinforced, particularly abundant surplus labor, which will inevitably have positive effect on economic growth in the long term. Based on the relation between resident population urbanization and economic growth, we can make the judgment that with the accelerated urbanization process in China, China's economy can maintain a growth of medium and high speed in the future. Secondly, unidirectional causality also exists between land urbanization rate and China's economic growth. However, different from resident population urbanization rate, it is the economic growth of China that promotes the increase of land urbanization rate and the increase of land urbanization rate cannot promote China's economic growth. No matter in the short term or in the long term, economic growth all has a positive effect on land urbanization rate. One possible explanation why land urbanization does not have effect on economic growth is that land urbanization is based on rapid enlargement in China. It does not match with the resident population urbanization and household registered population urbanization rate, whereas human factor is the key to promoting economic growth. The promoting effect of economic growth on land urbanization rate is related with the evaluation mechanism of the Chinese government officials. In China, government undertakes the city planning and construction. With the development of economy, government tends to reflect the growth results by enlarging city borders. Thirdly, the relation between the quality of urbanization and China's economic growth is a two-way causality. The improvement of urbanization quality has a cumulative positive effect on the economic growth of China, while economic growth has a negative effect on the improvement of urbanization quality in the short term and positive effect on economic growth in the long term. The improvement of urbanization quality is the manifestation of humanism. It meets the requirements of economic development in post-industrial era and will definitely have positive effects on economic growth. The improvement of urbanization quality depends on the increase of household registered population urbanization rate. The household registered population urbanization rate is featured by the improvement of public services, such as social security and medical security, which requires tremendous financial support and therefore cannot be fully realized in the short term. However, with the long-term growth of economy and accumulation of fiscal revenue, quality public services will definitely be provided to more city population, hence the difference in the long-term and short-term effects of economic growth on city quality.

\section{Suggestions}

By describing and analyzing the relation between urbanization and economic growth in China, the following suggestions on the future urbanization path in China can be proposed:

Firstly, the population urbanization rate must be continuously improved. The urbanization rate of resident population plays a positive facilitating role on economic growth. In 2015, the urbanization rate of China reached 
$56.1 \%$. However, compared to the urbanization rate of $85 \%$ in moderately developed countries and about $95 \%$ in Western developed countries, the urbanization in China still has great room for development and can continue playing a role in the promotion of economic growth. To improve population urbanization rate, there are two things that must be done. One is to optimize industrial structure. The process of urbanization is the process of population transferring from agriculture to industry and services. Developing industry and services and providing more jobs are the precondition. Especially for tertiary industry, it can create relatively more jobs and its proportion in total output should be increased continuously. The other is to reform the land system. Land system is one of the factors hindering the transformation of Chinese farmers into citizens. The current rural land system in China is collective ownership and the farmers have only the land usage right but not the land ownership. The rural land cannot be transferred freely. On the one hand, it goes against the scale production of agriculture; on the other hand, it prevents the farmers from getting the right and benefit of land transfer, making them bound by the land to a certain degree. So the rural land transfer system must be explored positively.

Secondly, the land urbanization rate must be strictly controlled. Judging from the empirical results, land urbanization cannot promote economic growth. Meanwhile, land urbanization in China has also brought about two issues. One is the potential risk of land finance of the government. Land-transferring fees are the main source of revenue of the Chinese local governments. The overdependence on land-transferring fees has the following consequences. On the one hand, it makes China's economy depend excessively on real estate industry and the capacity to resist financial risks declines. At the same time, being controlled by the leading role of real estate industry in the economic growth and path dependence in industrial structure make the steps of China's economic structural transformation and upgrade slow. On the other hand, it makes the price of the land increasingly rise, which is transmitted to commodity market and pushes the price of real estate too high, especially residential real estate in densely populated cities such as Beijing, Shanghai and Shenzhen. The high price of real estate is not only an economic issue of the big cities and megacities in China, but also a social issue which deserves our attention. The other is the orderless enlargement of city borders that intensifies the "city disease". Accompanying the rapid enlargement of urban land is the increasingly severe issue of the "home-work separation". The separation of living area for urban dwellers and work area increases commuting time and the resulting environmental pollution, wasting of resources, etc. According to statistics in List of Commuting Distance and Time in 50 Cities Nationwide, in 2015, except Hong Kong, Macau, Taiwan and Tibet, the average distance to work in provincial cities was $19.2 \mathrm{~km}$; commuting time was 52 minutes. The over-rapid land urbanization is one of the major reasons resulting in "city disease". Therefore the collection and management of land-transferring fees must be standardized by reforming and perfecting the fiscal mechanism and system such as the system of tax distribution, and guard against potential fiscal risks. Meanwhile, strictly control land urbanization rate by quantified index, take the new path of compact and intensive urbanization, and improve the well-being of Chinese urban dwellers.

Finally, the improvement of urbanization quality must be promoted. The low quality of urbanization in China is mainly reflected by the reality that the urbanization rate of household registered population is lower than that of the resident population. Judging from the empirical results, although the urbanization rate of resident population and urbanization quality are both the reason for economic growth, the latter plays a bigger role in economic growth. Taking cumulative impulse response functions as an example, at the 10th stage, by one standard deviation shock to resident population urbanization rate, the cumulative response of the growth rate of per capita GDP is 0.18 ; by one standard deviation shock to the quality of urbanization, the cumulative response of the growth rate of per capita GDP is 2.41 . Therefore the improvement of urbanization quality can better promote economic growth. To promote the improvement of urbanization quality, there are three things that must be done. The first is to reform the existing household registration system and promote the transfer from non-household registered resident population to household registered population. On the one hand, the existence of household registration system hinders the transfer of non-household registered population to relevant cities; on the other hand, it makes non-household registered population unable to enjoy social welfare related to household registration, aggravating the issue of malapportioned social resources and producing harmful results for economic growth. The second is to improve the level of urban public services. Public services are one of the benefits urban dwellers can enjoy. The important reason why people gather towards cities is that the economic efficiency and life efficiency is much higher in the cities than in rural areas, which is also a leading indicator of life efficiency. So in order to attract more rural population to transfer towards cities, the level of urban public services must be continuously improved. The third is to change the structure of public expenditure. To improve the urbanization rate of household registered population, the supporting fiscal input related to public services must be increased. At present, the public expenditure of China is still economic-construction finance, with economic construction expenditure taking an oversized proportion in total public expenditure. In the future, the 
proportion of public services in total public expenditure must be increased, so as to meet the needs of new household registered population for public services and social welfare.

\section{References}

Bertinelli, L., \& Zou, B. (2008). Does Urbanization Foster Human Capital Accumulation? The Journal of Developing Areas, 41(2), 171-184. https://doi.org/10.1353/jda.2008.0020

Bloom, D., Canning, D., \& Fink, G. (2008). Urbanization and the Wealth of Nations. Science, 319(5864), 772-775. https://doi.org/10.1126/science. 1153057

Chen, A. (2006). Urbanization in China and the Case of Fujian Province. Modern China, 32(1), 99-130. https://doi.org/10.1177/0097700405283503

Gibbs, J. (1966). Measures of Urbanization. Social Forces, 45(2), 170-177. https://doi.org/10.2307/2574387

Guan, J., \& Qiang, H. (2014). Theoretical and Empirical Study on the Relationship between Urbanization and Economic Growth in China. Journal of Industrial Technological Economics, 3(245), 33-41.

Hongling, Y., \& Teng, X. (2013). The Mismatch between Population Urbanization and Land Urbanization in China. Urban Planning Forum, 2(217), 10-15.

Kai-ming, G., Jiang-wen, Y., \& Liu-tang, G. (2015). Family Planning Policy, Urbanization and Growth. Finance Research, 11(425), 47-63.

Kong-lai, Z., Jing-jing, L., \& Fei-fei, Y. (2011). Empirical Analysis on the Relationship between China Urbanization and Economic Growth. Statistic Research, 9(28), 80-88.

Lampard, E. (1955). The History of Cities in the Economically Advanced Areas. Economic Development and Cultural Change, 3(2), 81-136. https://doi.org/10.1086/449680

Lampard, E. (1961). American Historians and the Study of Urbanization. The American Historical Review, 67(1), 49-61. https://doi.org/10.2307/1846261

Minh, D. (2002). An Analysis of Growth of Urbanization in Developing Economies. The Journal of Developing Areas, 36(1), 81-91. Retrieved from http://www.jstor.org/stable/4192903

Reiss, A. (1954). Economic Growth and the Rate of Urbanization: A Comment on the Paper by Davis and Golden. Economic Development and Cultural Change, 3(1), 27-29. https://doi.org/10.1086/449674

Schnore, L. (1964). Urbanization and Economic Development: The Demographic Contribution. The American Journal of Economics and Sociology, 23(1), 37-48. https://doi.org/10.1111/j.1536-7150.1964.tb00931.x

Ting, W. (2013). Impact of Urbanization on China's Economic Growth and Its Spatiotemporal Differentiation. Population Research, 9(37), 53-66.

Tisdale, H. (1942). The Process of Urbanization. Social Forces, 20(3), 311-316. https://doi.org/10.2307/3005615

Xue-qin, L., Dai, W., \& Wang-bin, R. (2013). Research on the mechanism of urbanization to economic increase in China. Geographical Research, 4(32), 691-700.

Zhong-qi, D., \& Yong-jun, C. (2015). China's Economic Growth Pattern in the Urbanization Process. Economic Theory and Economic Management, 12, 94-109.

Zi-Lian, L. (2013). A Study on the Causes of Population Urbanization Lagging Behind Land Urbanization. China Population, Resources and Environment, 11(23), 94-101.

\section{Copyrights}

Copyright for this article is retained by the author(s), with first publication rights granted to the journal.

This is an open-access article distributed under the terms and conditions of the Creative Commons Attribution license (http://creativecommons.org/licenses/by/4.0/). 